\title{
FORMAÇÃO DE BIOFILME APÓS ESTRESSE SUBLETAL POR Vibrio parahaemolyticus ISOLADOS DE CAMARÃO-ROSA (Farfantepenaeus paulensis)
}

\author{
FORMATION OF BIOFILM AFTER SUBLETAL STRESS BY Vibrio \\ parahaemolyticus ISOLATES FROM PINK SHRIMP (Farfantepenaeus \\ paulensis)
}

\author{
Janaina Viana da Rosa ${ }^{*}$ \\ Natália Volpato da Conceição ${ }^{1}$ \\ Izadora Perez ${ }^{1}$ \\ Cláudio Dias Timm ${ }^{1}$ \\ 1Universidade Federal de Pelotas, Pelotas, RS, Brasil. \\ *Autora para correspondência - janavrosa@yahoo.com.br
}

\section{Resumo}

O consumo de frutos do mar, como o camarão-rosa, contaminados com V. parahaemolyticus pode causar gastrenterite aguda. $\mathrm{O}$ objetivo deste trabalho foi verificar a capacidade de $V$. parahaemolyticus isolados de camarões provenientes do estuário da Lagoa dos Patos formarem biofilme após exposição a diferentes tipos de estresse subletal. Para obtenção das amostras, foram realizadas 12 coletas de Farfantepenaeus paulensis, durante o período de safra de 2016. As amostras foram analisadas quanto à presença de V. parahaemolyticus. As cepas foram avaliadas quanto à capacidade de produção de biofilme em placas de microtitulação, tanto antes como após serem submetidas a diferentes tipos de estresse subletal. V. parahaemolyticus foi isolado de $16,66 \%(2 / 12)$ das amostras. Uma das duas cepas isoladas foi capaz de formar biofilme, sendo classificada como fraca formadora de biofilme, a outra foi classificada como não formadora de biofilme. Nenhuma das cepas alterou sua capacidade de formar biofilme quando submetida aos estresses de $4{ }^{\circ} \mathrm{C}$ e $20{ }^{\circ} \mathrm{C}$; contudo, com relação aos estresses de $42{ }^{\circ} \mathrm{C}$ e pH ácido, cada cepa respondeu de uma maneira diferente.

Palavras-chave: camarão-rosa; contaminação; doenças transmitidas por alimentos.

\begin{abstract}
Consumption of seafood, such as pink shrimp, contaminated by $V$. parahaemolyticus can cause acute gastroenteritis. The objective this study was to verify the ability of $V$. parahaemolyticus isolated from shrimp from Lagoa dos Patos estuary to form biofilm after exposure to different types of sublethal stress. To obtain the samples, 12 collections of Farfantepenaeus paulensis were carried out during the 2016 harvest period. The samples were analyzed for the presence of $V$. parahaemolyticus. The strains were evaluated for biofilm production capacity on microtiter plates, both before and after being submitted to different types of sublethal stress. V. parahaemolyticus was isolated from $16.66 \%(2 / 12)$
\end{abstract}


of the samples. One of the two isolated strains was able to form biofilm, being classified as weak biofilm-forming; the other one was classified as non-biofilm-forming. None of the strains altered their ability to form biofilm when subjected to the stresses of $4{ }^{\circ} \mathrm{C}$ and $20{ }^{\circ} \mathrm{C}$; however, regarding the stresses of $42^{\circ} \mathrm{C}$ and $\mathrm{pH}$ acid, each strain responded differently.

Keywords: Contamination; foodborne illness; pink shrimp.

Recebido em: 24 novembro de 2016

Aceito em: 11 julho de 2017

\section{Introdução}

No Brasil, o consumo de pescado tem aumentado, alcançando o patamar de $14,5 \mathrm{~kg} / \mathrm{habitante} /$ ano em 2013, sendo que o consumo mínimo recomendado pela Organização Mundial de Saúde (OMS) foi de $12 \mathrm{~kg} /$ habitante/ano e o consumo mundial foi de $18,8 \mathrm{~kg} /$ habitante/ano, também no ano de $2013^{(1)}$. Um dos fatores que contribui para esse aumento no consumo do pescado é a preocupação com a alimentação saudável e a qualidade de vida. As características nutricionais dos camarões fazem deles um alimento privilegiado, pois são fontes de proteínas e ainda contém cálcio, ferro, iodo, zinco e vitaminas B1, B2 e B12. Embora contenha altos níveis de colesterol, um consumo moderado não oferece riscos para a saúde cardiovascular ${ }^{(2)}$. Farfantepenaeus paulensis (camarão-rosa) é encontrado ao longo da região costeira brasileira, a partir de Ilhéus, Bahia (BA), estendendo-se pelo Uruguai até o litoral nordeste da Argentina ${ }^{(3)}$.

A Lagoa dos Patos, no Rio Grande do Sul (RS), possui uma comunicação estuário-oceano que é influenciada por fatores meteorológicos, os quais interferem na entrada de água marinha ${ }^{(4)}$. Devido a este fator, o período de safra do camarão no estuário ocorre durante o verão e início de outono. Para garantir a qualidade desses alimentos, é necessário o correto manuseio durante a sua captura, processamento, armazenamento, transporte e comercialização. Segundo Baldisserotto ${ }^{(5)}$, faltam estudos sobre a qualidade do pescado continental vendido ao consumidor no Rio Grande do Sul e sobre a ocorrência de agentes etiológicos de doenças transmitidas por alimentos (DTA) em pescados da região, em especial do estuário da Lagoa dos Patos, o que constitui a base indispensável para traçar planos efetivos de controle da sua transmissão para os consumidores.

Vibrio spp. são bactérias Gram negativas que possuem formato de bastonete e são móveis, contendo geralmente um único flagelo polar. São encontradas naturalmente em ambientes marinhos ou estuarinos, podendo estar livres ou ligadas a sedimentos ${ }^{(6)}$. V. cholerae, V. parahaemolyticus e $V$. vulnificus são as espécies melhor documentadas como patógenos humanos ${ }^{(7)}$. V. parahaemolyticus é mais facilmente encontrado em locais com temperatura da água superior a $15^{\circ} \mathrm{C}^{(8)}$. Essa espécie de micro-organismo é halofílica, podendo ser encontrada em ambientes com salinidade entre 3\% e $8 \%$. É um patógeno que pode causar gastrenterite aguda pelo consumo de frutos do mar contaminados, crus ou mal cozidos, e pode também provocar infecções em feridas abertas que tenham sido expostas à água do mar. Em casos raros, a infecção por $V$. parahaemolyticus pode ser fatal ${ }^{(7)}$. O gene ToxR está presente em todas as cepas de $V$. parahaemolyticus ${ }^{(9-11)}$, podendo ser encontrado em isolados patogênicos ou não patogênicos ${ }^{(12)}$. Este gene possui um fragmento de 368 pares de base (pdb) 
específico para Vibrio parahaemolyticus que é encontrado em todos os isolados ${ }^{(13)}$. O uso deste gene para identificação de $V$. parahaemolyticus através da reação em cadeia da polimerase (PCR) é específico, sensível e rápido ${ }^{(9,13,14)}$, pois, além de $V$. parahaemolyticus ser detectado em todas as amostras analisadas, não ocorrem resultados falsos positivos ${ }^{(10,15)}$.

Biofilme bacteriano é uma comunidade de micro-organismos sésseis que são capazes de se agregar e aderir a uma superfície, embebidos em uma matriz extracelular formada por exopolissacarídeos ${ }^{(16)}$. Algumas células de Vibrio podem se tornar resistentes a fatores ecológicos, tais como altas ou baixas temperaturas ou $\mathrm{pH}$ baixo. Tanto essa resistência pode levar ao aumento da capacidade de formar biofilme, como também a alta capacidade de formar biofilme pode levar à resistência a diferentes tipos de estresse, dificultando a eliminação da bactéria durante a preparação dos pescados para o consumo $^{(17)}$.

O objetivo deste trabalho foi verificar a capacidade de $V$. parahaemolyticus isolados de camarões provenientes do estuário da Lagoa dos Patos formarem biofilme após exposição a diferentes tipos de estresse subletal.

\section{Materiais e Métodos}

Para obtenção das amostras, foram realizadas 12 coletas de $F$. paulensis no mercado público da cidade de Pelotas (RS), durante o período de safra, nos meses de fevereiro a abril de 2016. Todos os camarões eram provenientes do estuário da Lagoa dos Patos. As amostras foram colocadas em saco estéril e imediatamente encaminhadas em caixas isotérmicas com gelo ao laboratório para análise.

A pesquisa de Vibrio spp. foi feita conforme recomendado por U. S. Food and Drug Administration - $\mathrm{FDA}^{(7)}$, com modificações. Foram colocados $25 \mathrm{~g}$ de $F$. paulensis em sacos plásticos estéreis contendo $225 \mathrm{~mL}$ de Água Peptonada Alcalina (Himedia, Mumbai, Índia), pH 8,5, com 3\% de $\mathrm{NaCl}$ (APA-3\% NaCl), homogeneizados por 5 minutos e incubados a $37{ }^{\circ} \mathrm{C}$ por 24 horas para enriquecimento. A partir do material da superfície dessas culturas foram feitas semeaduras por esgotamento em ágar Tiossulfato Citrato Bile Sacarose (TCBS, Himedia) e incubação a $37{ }^{\circ} \mathrm{C}$ por 24 horas para obtenção de colônias isoladas. Até três colônias típicas de cada placa foram semeadas em APA-3\% NaCl e, após incubação a $37^{\circ} \mathrm{C}$ por 24 horas, a cultura foi misturada com $20 \%$ de glicerol para manutenção de estoque a $-70^{\circ} \mathrm{C}$. Os isolados foram recuperados em $\mathrm{APA}-3 \% \mathrm{NaCl}$ a $37^{\circ} \mathrm{C}$ por 24 horas, a cada três meses para manutenção do estoque ou quando necessário.

Os isolados foram recuperados e seus DNAs extraídos conforme Sambrook e Russel ${ }^{(18)}$. Resumidamente, o pellet obtido por centrifugação de $1 \mathrm{~mL}$ de cultura previamente recuperada por 24 horas a $37^{\circ} \mathrm{C}$ em APA-3\% NaCl foi ressuspendido em $100 \mu \mathrm{L}$ de tampão STES [Tris-HCl 0,2 M-SDS 0,1\% (m/v), EDTA 0,01 M, pH 7,6], aos quais foram adicionados $50 \mu \mathrm{L}$ de pérolas de vidro e 100 $\mu \mathrm{L}$ de fenol/clorofórmio. Após homogeneização por $1 \mathrm{~min}$, a mistura foi centrifugada a $13.000 \mathrm{~g}$ por 5 min. O sobrenadante $(100 \mu \mathrm{L})$ foi coletado e precipitado em $200 \mu \mathrm{L}$ de etanol absoluto e $10 \mu \mathrm{L}$ de $\mathrm{NaCl} 5 \mathrm{M}$ a $-70{ }^{\circ} \mathrm{C}$ por $30 \mathrm{~min}$. Uma nova centrifugação foi realizada a $13.000 \mathrm{~g}$ por $20 \mathrm{~min}$, o sobrenadante descartado e o pellet lavado com etanol a 70\%. Após eluição em $40 \mu \mathrm{L}$ de tampão de 
eluição (Tris-HCl $10 \mathrm{mM}$, EDTA $1 \mathrm{mM}, \mathrm{pH}$ 7,4), foi adicionado $1 \mu \mathrm{L}$ de RNAse $(10 \mu \mathrm{g} / \mu \mathrm{L})$. O DNA extraído foi estocado a $-70^{\circ} \mathrm{C}$.

Os isolados de Vibrio foram analisados pela PCR para pesquisa dos genes toxR (Tabela 1), para identificação de $V$. parahaemolyticus conforme Bilung et al. ${ }^{(19)}$, com modificações. Cada reação teve um volume final de $20 \mu \mathrm{L}$. Foram utilizados $10 \mu \mathrm{L}$ de Master Mix (Promega, Madison, EUA), $1 \mu \mathrm{L}$ (10 pmol) de cada primer (Sigma- Aldrich, São Paulo, Brasil), 1,2 $\mu \mathrm{L}$ de DNA e 6,8 $\mu \mathrm{L}$ de água (Promega) para completar o volume da reação. A amplificação foi realizada em termociclador TC3000 (Techne, Stone, Reino Unido) com o seguinte programa: desnaturação inicial de $96{ }^{\circ} \mathrm{C}$ por 5 min, seguido de 20 ciclos de desnaturação a $94{ }^{\circ} \mathrm{C}$ por $1 \mathrm{~min}$, anelamento dos primers a $63{ }^{\circ} \mathrm{C}$ por 1,5 min, extensão a $72{ }^{\circ} \mathrm{C}$ por 1,5 min e extensão final a $72{ }^{\circ} \mathrm{C}$ por $7 \mathrm{~min}$. Os produtos da PCR foram corados com GelRed (Uniscience, São Paulo, Brasil) e a eletroforese foi realizada em gel de agarose a 1,8\%. Como controle positivo, foi utilizada a cepa de V. parahaemolyticus ATCC 17802.

Tabela 1. Primers utilizados na identificação de $V$. parahaemolyticus

\begin{tabular}{llcc}
\hline Primer & \multicolumn{1}{c}{ Sequência (5'a 3') } & $\begin{array}{c}\text { Tamanho da } \\
\text { amplificação (pb) }\end{array}$ & Referência \\
\hline ToxR-a & GTCTTCTGACGCAATCGTTG & 368 & KIM et al. $^{(9)}$ \\
ToxR-b & ATACGAGTGGTTGCTGTCATG & & \\
\hline
\end{tabular}

As cepas foram avaliadas quanto à capacidade de produção de biofilme em placas de microtitulação de 96 poços (Nunclon, Nune, Roskilde, Denmark), seguindo a técnica descrita por Janssens et al. ${ }^{(20)}$, com modificações, de forma a adaptar o método para $V$. parahaemolyticus. Foram colocados $200 \mu \mathrm{L}$ de caldo APA-3\% NaCl em cada poço da placa de microtitulação adicionados de $2 \mu \mathrm{L}$ de culturas overnight em APA-3\% NaCl de cada cepa padronizada em espectrofotômetro a $600 \mathrm{~nm}$ para valor 0,5 de densidade ótica (DO), o que corresponde a aproximadamente 5,5.10 $\mathrm{UFC} / \mathrm{mL}$. Poços com 200 $\mu \mathrm{L}$ de caldo APA-3\% NaCl, sem cultura bacteriana, foram utilizados como controle. Em seguida, a tampa foi colocada sobre a placa, que foi incubada durante 48 horas a $37^{\circ} \mathrm{C}$ sem agitação. As tampas das placas possuem protuberâncias em forma de cone, cada uma delas entrando em contato unicamente com um poço. Como as protuberâncias estão em contato com o líquido contido em cada poço, as bactérias irão se aderir e os biofilmes serão formados sobre elas. O biofilme avaliado foi apenas o formado nas protuberâncias da tampa. Posteriormente, as tampas foram lavadas em $200 \mu \mathrm{L}$ de solução salina tamponada com fosfato $(\mathrm{PBS}, 0,1 \mathrm{M}, \mathrm{pH} 7,0)$. O material que permaneceu ligado à tampa foi corado durante $30 \mathrm{~min} \operatorname{com} 200 \mu \mathrm{L}$ de cristal violeta $0,1 \%(\mathrm{~m} / \mathrm{v})$, lavado em água destilada estéril $(200 \mu \mathrm{L})$ e a tampa foi seca em temperatura ambiente por $30 \mathrm{~min}$. O biofilme com corante foi extraído com ácido acético glacial 30\% (200 $\mu \mathrm{L})$ utilizando-se outra placa de 96 poços. Para quantificação da formação de biofilmes, a $\mathrm{DO}_{570}$ de cada poço contendo o biofilme com corante e já extraído foi medida utilizando-se leitor de placas de microtitulação. Foram realizadas três repetições de cada teste. A análise da variância foi realizada com o programa STATISTIX ${ }^{\mathrm{O}}$ (2003), considerando valor do nível de significância de $\mathrm{P}<0,05$. Cada cepa foi classificada como não formadora de biofilme, fraca formadora, moderada formadora ou forte formadora, de acordo com os procedimentos sugeridos por Stepanovic et al. ${ }^{(21)}$. O ponto de corte (DOc) foi definido como três desvios padrões acima da média das DOs dos controles. A classificação foi determinada conforme segue.

$\mathrm{DO} \leq \mathrm{DOc}=$ não formadora

$\mathrm{DOc}<\mathrm{DO} \leq 2 \times \mathrm{DOc}=$ fraca formadora 
$2 \times \mathrm{DOc}<\mathrm{DO} \leq 4 \times \mathrm{DOc}=$ moderada formadora

$4 \times \mathrm{DOc}<\mathrm{DO}=$ forte formadora

A capacidade de produção de biofilme após as cepas serem submetidas a estresse subletal foi testada. Para exposição das células ao choque de calor, culturas overnight em APA-3\% NaCl foram mantidas em banho-maria a $42{ }^{\circ} \mathrm{C}$ por 45 min, segundo Chang et al. ${ }^{(22)}$. Para exposição ao choque de frio, culturas overnight em APA-3\% NaCl foram mantidas a $20^{\circ} \mathrm{C}$ durante 4 horas, de acordo com Lin et al. ${ }^{(23)}$. As células também foram estressadas a $4{ }^{\circ} \mathrm{C}$ durante 4 horas. Os procedimentos descritos por Wong et al. ${ }^{(24)}$ foram utilizados para estressar as células bacterianas em ambiente ácido: culturas overnight em APA-3\% NaCl tiveram o $\mathrm{pH}$ ajustado para $5,0 \mathrm{com} \mathrm{HCl} 12 \mathrm{~N}$ e foram incubadas a $37^{\circ} \mathrm{C}$ durante 30 $\min$.

\section{Resultados e Discussão}

$V$. parahaemolyticus foi isolado de 16,66\% (2/12) das amostras. Este é o segundo registro da ocorrência de $V$. parahaemolyticus em $F$. paulensis oriundo do estuário da Lagoa dos Patos. Milan et al. ${ }^{(25)}$ encontraram o micro-organismo em 46,15\% (6/13) das amostras que analisaram. Mesmo o pequeno número de amostras utilizado nesses dois estudos já foi suficiente para demonstrar que $V$. parahaemolyticus está presente nos camarões capturados no estuário da Lagoa dos Patos, salientando a possibilidade do micro-organismo chegar à mesa do consumidor, devido ao alto consumo na região deste tipo de crustáceo durante o período de safra.

Uma das duas cepas isoladas foi capaz de formar biofilme, sendo classificada como fraca formadora de biofilme. A análise de variância demonstrou não haver efeito estatístico das repetições sobre os valores de DO. De acordo com Donlan e Costerton ${ }^{(16)}$, V. parahaemolyticus é capaz de produzir diferentes tipos de fatores de adesão, como pili e flagelo, que permitem às bactérias aderirem à superfície e iniciar a formação de biofilme. A formação de biofilme por cepa de $V$. parahaemolyticus isolada de $F$. paulensis ressalta os cuidados que devem ser adotados na indústria de pescados com relação à sanitização e higienização dos materiais e equipamentos utilizados na manipulação do alimento, já que, após a formação do biofilme, sua eliminação é dificultada pois as bactérias passam a apresentar reduzidas taxas metabólicas e de crescimento. Além disso, a matriz de polímeros extracelulares passa a agir como um adsorvente e ainda essa mesma matriz pode reduzir a penetração de sanitizantes ${ }^{(26)}$.

Após as cepas terem sido submetidas aos diferentes tipos de estresse subletais, não houve mudança na categoria da cepa, segundo Stepanovic et al. ${ }^{(21)}$, na formação de biofilmes quando as células foram estressadas a $4{ }^{\circ} \mathrm{C}$ e $20^{\circ} \mathrm{C}$. Já a $42{ }^{\circ} \mathrm{C}$ e pH ácido, cada cepa respondeu de uma maneira diferente. A cepa que era inicialmente não formadora de biofilme passou a ser fraca formadora em ambos os casos e a cepa que era fraca formadora, perdeu a capacidade de formar biofilme após esses dois tipos de estresse. Mizan et al. ${ }^{(27)}$ relataram que $V$. parahaemolyticus pode formar biofilme em placas de microtitulação devido a diferentes condições de estresse, como a temperatura, que pode influenciar a produção de polímeros extracelulares, os quais podem aumentar a formação biofilme. Desvios de $\mathrm{pH}$ para valores inferiores ou superiores a 7 irão influenciar o desenvolvimento e a atividade da comunidade microbiana, pois o $\mathrm{pH}$ tem um efeito preponderante no metabolismo dos micro- 
$\operatorname{organismos}^{(28)}$, influenciando a ação dos desinfetantes ou mesmo podendo causar o aumento dos biofilmes $^{(29)}$. Em trabalho realizado por Lin et al. ${ }^{(30)}$, células de $V$. parahaemolyticus foram expostas a tensões subletais como calor a $42^{\circ} \mathrm{C} \mathrm{e} \mathrm{pH}$ ácido para depois se analisar sua resistência a sanitizantes. Os autores verificaram que esses fatores estressantes aumentaram a resistência de $V$. parahaemolyticus aos produtos utilizados.

Dentro da indústria de alimentos podem ser utilizados diferentes métodos de limpeza, como também diferentes desinfetantes e a eficácia dos desinfetantes depende essencialmente de fatores como temperatura e $\mathrm{pH}$. De uma forma geral, os desinfetantes atuam melhor a temperaturas acima da temperatura ambiente e cada desinfetante tem uma gama de valores de $\mathrm{pH}$ em que é mais eficaz ${ }^{(31)}$. No presente estudo, foi possível observar que alguns tipos de estresse influenciam a formação de biofilme, seja favorecendo ou inibindo a sua formação, o que depende da cepa e do tipo de estresse pelo qual passou. Sendo assim, dentro da indústria alimentícia, a exposição a estresses subletais pode afetar a formação de biofilme e ocasionar dificuldades na remoção dos micro-organismos, que passam a ser uma potencial fonte de contaminação para os alimentos produzidos.

\section{Conclusão}

Camarões da espécie $F$. paulensis são hospedeiros de $V$. parahaemolyticus e estes podem ser formadores de biofilme, o que poderia dificultar a eliminação desses micro-organismos quando presentes em uma indústria de alimentos. Os dois isolados apresentaram comportamento distinto quando expostos a estresses subletais (calor a $42{ }^{\circ} \mathrm{C}$, frio a $4{ }^{\circ} \mathrm{C}$ e a $20^{\circ} \mathrm{Ce} \mathrm{pH}$ ácido). Esses resultados demonstram que algumas condições às quais o alimento é submetido podem induzir ao aumento da capacidade de formar biofilme, que é, porém, cepa dependente.

\section{Referências}

1. Ministério da Pesca e Aquicultura- MPA. Potencial brasileiro [periódico na Internet]. 2014. [citado 2016 Out 21]. Disponível em: 〈http://www.mpa.gov.br/aquicultura/potencial-brasileiro〉.

2. Huss HH, Reilly A, Embrakeb PKB. Prevention and control of hazard in seafood. Food Control. 2000; 11:149-156.

3. Krummenauer D, Júnior W, Cavalli R, Peixoto S, Zogbi P. Viabilidade do cultivo do camarão-rosa Farfantepenaeus paulensis (Crustácea, Decapoda) em gaiolas sob diferentes densidades durante o outono no sul do Brasil. Ciência Rural. 2006; 36(1):252-257.

4. Möller O, Fernandes E. Hidrologia e hidrodinâmica. In: Seeliger U, Odebrecht C,editores. O estuário da Lagoa dos Patos: um século de transformações. Rio Grande: FURG; 2010. p. 17-27. Português.

5. Baldisserotto B. Piscicultura continental no Rio Grande do Sul: situação atual, problemas e perspectivas para o futuro. Ciência Rural.2009; 39(1):291-299.

6. Baumann P, Schubert RHW. Family II: Vibrionaceae. In: Krieg NR, Holt JG, editores. Bergey's manual of systematic bacteriology. Baltimore LON: Williams \& Wilkins Co.; 1984. p. 516-550. Inglês. 
7. Kaysner CA, Depaola Jr. Vibrio. U.S. Food and Drug Administration, Bacteriological Analytical ManualBAM [periódico na Internet]. 2004 [acessado 2016 Out 19]. Disponível em:<http://www.fda.gov/Food/FoodScienceResearch/LaboratoryMethods/BacteriologicalAnalyticalManual BAM/ucm070830.htm>.

8. Su YC, Liu C. Vibrio parahaemolyticus: a concern of seafood safety. Food Microbiology.2007; 24:549-58.

9. Kim YB, Okuda J, Matsumoto C, Takahashi N, Hashimoto S, Nishibuchi M. Identification of Vibrio parahaemolyticus strains at the species level by PCR targeted to the toxR gene. Journal of Clinical Microbiology.1999; 37(4):1173-1177.

10. Dileep V, Kumar HS, Kumar Y, Nishibuchi M, Karunasagar I, Karunasagar I. Application of polymerase chain reaction for detection of Vibrio parahaemolyticus associated with tropical seafoods and coastal environment. Letters in Applied Microbiology. 2003; 36: 423-427.

11. Sujeewa AKW, Norrakiah AS, Laina M. Prevalence of toxic genes of Vibrio parahaemolyticus in shrimps (Penaeus monodon) and culture environment. International Food Research Journal. 2009; 16:89-95.

12. Sechi LA, Dupre I, Deriu A, Fadda G, Zanetti S.. Distribution of Vibrio cholerae virulence genes among different Vibrio species isolated in Sardinia, Italy. Journal of Applied Microbiology. 2000; 88: 475-481.

13. Zulkifli Y, Alitheen NB, Son R, Yeap SK, Lesley MB, Raha AR. Identification of Vibrio parahaemolyticus isolates by PCR targeted to the toxR gene and detection of virulence genes. International Food Research Journal. 2009; 16: 289-296.

14. Sheng X, Ting YP, Pehkonen SO. Force measurements of bacterial adhesion on metals using a cell probe atomic force microscope. Journal of Colloid and Interface Science. 2007; 310:661-669.

15. Croci L, Suffredin E, Cozz L, Tot L, Ottavian D, Pruzz C, Serrator P, Fischett R, Goffred E, Loffred G, Mioni R. Comparison of different biochemical and molecular methods for the identification of Vibrio parahaemolyticus. Journal Applied Microbiology. 2007; 102:229-237.

16. Donlan RM, Costerton JM. Biofilms: survival mechanisms of clinically relevant microorganisms. Clinical Microbiology Reviews. 2002; 15:167-193.

17. Castro-Rosas J, Escartín EF. Adhesion and colonization of $V$. cholerae O1 on shrimp and crab carapace. Journal of Food Protection.2002; 65:492-498.

18. Sambrook J, Russel DW. Molecular Cloning: A Laboratory Manual. 3.ed. Nova York: Cold Spring Harbor Laboratory Press; 2001. 999p. Inglês.

19. Bilung ML, Radu S, Bahaman AR, Rahim RA, Napis S. Random amplified polymorphic DNA-PCR typing of Vibrio parahaemolyticus isolated from local cockles (Anadara granosa). American Journal of Immunology.2005; 1:31-36.

20. Janssens JCA, Steenackers H, Robijns S, Gellens E, Levin J, Zhao H, Hermans K, Coster D, Verhoeven TL, Marchal K, Vanderleyden J, DeVos DE, DeKeersmaecker SCJ. Brominated furanones inhibit biofilm formation by Salmonella enterica SerovarTyphimurium. Applied Environmental Microbiology.2008; 74(21):6639-6648.

21. Stepanovic S, Vukovic D, Dakic I, Savic B, Svabic-Vlahovic M. A modified microtiter-plate test for quantification of staphylococcal biofilm formation. Journal of Microbiological Methods.2000; 40:175-179.

22. Chang CM, Chiang ML, Chou CC. Responses of heat-shocked Vibrio parahaemolyticus to subsequent physical and chemical stresses. Journal of Food Protection.2004; 67:2183-2188.

23. Lin C, Yu RC, Chou CC. Susceptibility of Vibrio parahaemolyticus to various environmental stresses after cold shock treatment. International Journal of Food Microbiology. 2004; 92:207-215. 
24. Wong HC, Peng PY, Han JM, Chang CY, Lan SL. Effect of mild acid treatment on the survival, enteropathogenicity, and protein production in Vibrio parahaemolyticus. Infection and Immunity.1998; 66(7):3066-3071.

25. Milan C,Silveira DR, Rosa JV, Timm CD. Vibrio parahaemolyticus isolados de pescados do estuário da Lagoa dos Patos. Revista doInstituto Adolfo Lutz. 2015; 74(2):149-153.

26. Gilbert P, Allison DG, Mcbain AJ. Biofilms in vitro and in vivo: do singular mechanisms imply crossresistance? Jounal of Applied Microbiology. 2002; 92:98-110.

27. Mizan MFR, Jahid IK, Kim MH, Lee KH, Kim TJ, Ha SD. Variability of biofilm formation correlates with hydrophobicity and quorum sensing among Vibrio parahaemolyticus isolates from food contact surfaces and distribution of genes involved in biofilm formation. Biofouling. 2016; 32(4):497-509.

28. Bott, TR. 1995. Fouling of heath exchangers. Amsterdam, Netherlands: Elsevier science B. V. 546p.

29. Environmental Protection Agency, EPA. Health risks from microbial growth and biofilms in drinking water distribution systems environmental protection agency. Pennsylvania, 2002.

30. Lin, MH, Tsai TY, Hsieh SC, Yu RC, Chou CC. Susceptibility of Vibrio parahaemolyticus to disinfectants after prior exposure to sublethal stress. FoodMicrobiology.2013; 34:202-206.

31. Wirtanen G. Biofilm formation and its elimination from food processing equipament. VTT publications $251 ; 1995$. 